\title{
Preparing for sea-level rise through adaptive managed retreat of a New Zealand stormwater and wastewater network
}

\author{
Kool, Rick; Lawrence, Judy; Drews, Martin; Bell, Robert
}

Published in:

Infrastructures

Link to article, DOI:

10.3390/infrastructures5110092

Publication date:

2020

Document Version

Publisher's PDF, also known as Version of record

Link back to DTU Orbit

Citation (APA):

Kool, R., Lawrence, J., Drews, M., \& Bell, R. (2020). Preparing for sea-level rise through adaptive managed retreat of a New Zealand stormwater and wastewater network. Infrastructures, 5(11), [92].

https://doi.org/10.3390/infrastructures5110092

\section{General rights}

Copyright and moral rights for the publications made accessible in the public portal are retained by the authors and/or other copyright owners and it is a condition of accessing publications that users recognise and abide by the legal requirements associated with these rights.

- Users may download and print one copy of any publication from the public portal for the purpose of private study or research.

- You may not further distribute the material or use it for any profit-making activity or commercial gain

- You may freely distribute the URL identifying the publication in the public portal

If you believe that this document breaches copyright please contact us providing details, and we will remove access to the work immediately and investigate your claim 
Article

\title{
Preparing for Sea-Level Rise through Adaptive Managed Retreat of a New Zealand Stormwater and Wastewater Network
}

\author{
Rick Kool $^{1,2}$, Judy Lawrence ${ }^{1, *(1)}$, Martin Drews ${ }^{2}$ (I) and Robert Bell ${ }^{3}$ (i) \\ 1 New Zealand Climate Change Research Institute, Victoria University of Wellington, \\ 6012 Wellington, New Zealand; rick.kool@yahoo.co.uk \\ 2 Department of Technology, Management and Economics, Technical University of Denmark, \\ 2800 Kgs. Lyngby, Denmark; mard@dtu.dk \\ 3 National Institute of Water and Atmospheric Research, 3251 Hamilton, New Zealand; rob.bell@niwa.co.nz \\ * Correspondence: judy.lawrence@vuw.ac.nz
}

Received: 6 October 2020; Accepted: 16 October 2020; Published: 1 November 2020

check for updates

\begin{abstract}
Sea-level rise increasingly affects low-lying and exposed coastal communities due to climate change. These communities rely upon the delivery of stormwater and wastewater services which are often co-located underground in coastal areas. Due to sea-level rise and associated compounding climate-related hazards, managing these networks will progressively challenge local governments as climate change advances. Thus, responsible agencies must reconcile maintaining Levels of Service as the impacts of climate change worsen over the coming decades and beyond. A critical question is whether such networks can continue to be adapted/protected over time to retain Levels of Service, or whether eventual retreat may be the only viable adaptation option? If so, at what performance threshold? In this paper, we explore these questions for stormwater and wastewater, using a dynamic adaptive pathway planning (DAPP) approach designed to address thresholds and increasing risk over time. Involving key local stakeholders, we here use DAPP to identify thresholds for stormwater and wastewater services and retreat options, and for developing a comprehensive and area-specific retreat strategy comprising pathway portfolios, retreat phases, potential land use changes, and for exploring pathway conflicts and synergies. The result is a prototype for an area near Wellington, New Zealand, where a managed retreat of water infrastructure is being considered at some future juncture. Dynamic adaptive strategies for managed retreats can help to reduce future disruption from coastal flooding, signal land use changes early, inform maintenance, and allow for gradual budget adjustments by the agencies that can manage expenditure over time. We present this stepwise process in a pathway form that can be communicated spatially and visually, thereby making a retreat a more manageable, sequenced, adaptation option for water agencies, and the communities they serve.
\end{abstract}

Keywords: managed retreat; dynamic adaptive policy pathways; sea-level rise; water infrastructure; stormwater; wastewater; coastal flooding; climate change

\section{Introduction}

Sea-level rise (SLR) is one of the most severe climate change impacts affecting low-lying and exposed coastal communities both globally and locally, from extensive coastal flooding [1-5] to more shoreline erosion of sand/gravel systems [6,7]. Consequences and compounding hazards induced by SLR include more frequent flooding and increasing erosion, groundwater levels, saltwater intrusion, liquefaction risk, and drainage problems. In New Zealand, rising sea levels especially threaten coastal infrastructure, communities, and low-lying ecosystems [8-12]. National-scale assessments 
indicate that wastewater and stormwater infrastructure are more exposed to SLR than other coastal infrastructure $[10,13,14]$.

Uncertainty in future mean sea level rise is relatively small up to 2050 projected to be $0.25-0.35 \mathrm{~m}[5,8]$. Beyond this time horizon, the uncertainty range widens considerably and is highly dependent on future emissions as well as potential tipping points like the irreversible instabilities of polar ice sheets in Greenland and West Antarctica due to climate change [5]. In some locations like Florida [15,16] and New Zealand [11], the increase in local groundwater tables resulting from SLR is severely impacting stormwater and wastewater systems and pumping stations. Pressurized parts of the conveyance system are more mildly affected [11]. It is expected that the ongoing increase in mean sea level (rather than episodic coastal flooding events) will have the most wide-ranging impacts on the performance of drainage network systems. Several studies highlight decreases in drainage discharge capacity [15-18] and rising groundwater issues $[11,15,17-20]$ in coastal environments as a direct or indirect result of SLR.

The reliance of coastal communities on the delivery of the abovementioned critical network services raises the question of how responsible water agencies can maintain adequate Levels of Service as the impacts of climate change gradually increase. The two central challenges are (i) whether the networks can continue to be adapted (and/or protected) over time to retain Levels of Service, or whether they will eventually require a full or partial retreat (along with the community), and (ii) if so, at what performance or adaptation threshold (Section 2.2). Further, if retreat is the only viable long-term adaptation option, then a retreat strategy will have to be implemented in a staged manner over decades.

Local governments in New Zealand have a statutory mandate to address the effects of significant natural-hazard risk and climate change effects, which extends to assessing the delivery of services and the wellbeing of communities, e.g., planning to avoid and mitigate adverse effects of natural hazards, reduce flood risk, and delivery of water services for the well-being of communities. To date, the approach taken by local government has largely been to address impacts of flooding (including from SLR) on water infrastructure, as impacts emerge [21]. This reactive strategy may suffice in the short-term (provided any inevitable service failures can be managed in a timely and acceptable manner), but may compound the impacts and constrain future options in the coming decades as the compound effects of SLR, coastal flooding and heavy rainfall events more often reach performance thresholds locally. To address the constraints of short-term management of water infrastructure, a more strategic approach is called for if services are to be climate-proof in the face of ongoing sea-level rise and the compound hazards. In order to keep providing reliable services in the context of deepening climatic uncertainty, the limited available resources to upgrade networks will need to be invested strategically in climate adaptation [22]. Several councils in New Zealand are currently starting to implement or develop managed retreat strategies, as an adaptation to ongoing compound natural hazards at the coast. Hence, in some locations, retreat will be an inevitable response due to physical and affordability constraints and it has been judged prudent in national guidance and directions to manage such a response to avoid further unavoidable damage, disruption, public safety, and losses [23,24].

We define managed retreat as planned retreat that removes people and their assets, pre-emptively and permanently, away from hazards such as sea-level rise and flooding [24]. Siders [25] concludes that managed retreat often takes place ad hoc, focuses on risk reduction, and is typically isolated from broader societal goals. Instead, they recommend long-term strategic retreat aimed at contributing to societal goals. Barriers that make managed retreat difficult to implement in practice include the short-term economic gains in coastal development; imperfect risk perceptions, subsidized insurance rates, and disaster recovery costs; misaligned incentives between residents, local officials and national governments, and a preference for the status quo [25].

The objective of our research was to develop a prototype for guiding the development of sequenced strategies for managed retreat that can address the specific challenges based on an empirical situation near Wellington in New Zealand. There has been increased focus in New Zealand on managed retreat as the inevitable adaptation for addressing ongoing SLR in low-lying coastal areas where there are 
affordability and physical limits [24]. In this paper, other hard and soft coastal adaptation options that have been used to date are not considered except where they are part of a strategy for retreat of the water infrastructure. Our prototype approach developed from stakeholder consultations anticipates the onset of SLR-related impacts by systematically exploring a number of early actions and longer-term options for alternative pathways. This will enable an orderly and transparent transition to the retreat of the water infrastructure, while investigating a possible spatial sequence for retreat and Levels of Service for stormwater and wastewater. It is envisaged that the transition could be in tandem with, before or after, community retreat, but importantly before unacceptable cumulative damage and Levels of Service thresholds are reached.

New Zealand's national coastal hazards and climate change guidance recommends a multi-future scenario approach for integrating SLR projections into land-use planning and engineering design, with the primary purpose of stress-testing adaptation options and actions against locally determined adaptation thresholds $[8,26]$. To explore the retreat options, we applied an adaptive policy pathways approach (DAPP) [27] to current water infrastructure. To reflect that adaptations of stormwater and wastewater networks are not exclusively a technical issue, but also encompasses socio-political dimensions, we explored the interface between water services and a community retreat. Infrastructure serves the needs and well-being of the people in the area who are affected by the impacts of SLR impacts and therefore need to adapt $[22,28]$.

While the DAPP approach has previously been applied at the community level and for large-scale projects (e.g., the Delta Project in The Netherlands [29]), little research has so far been undertaken on its applicability as a framework for addressing the adaptation of stormwater and wastewater networks serving communities. Notable exceptions include a DAPP approach in Singapore and in London $[30,31]$ to investigate stormwater management and infrastructure adaptation pathways using preselected trajectories based on a cost benefit analysis, to enable a better understanding of adaptation timing. Radhakrishnan [32] applied a DAPP approach to the case of fluvial flood protection in the urban setting of Can Tho, Vietnam by adding a coping capacity component, reflecting the community coping capabilities at different scales. They derived no-regret actions by combining short-term citizen initiatives with long-term planning measures that could potentially delay adaptation thresholds (ATs). We found no empirical studies in the literature about how stormwater and wastewater networks can be retreated as sea level rises.

Section 2 (Methodology) describes the study area, the DAPP approach, our analysis framework, and principal stakeholder interactions. Section 3 (Results) presents our analyses, including the resulting prototype of spatial sequencing for retreat and Levels of Service, which is examined and evaluated in Section 4 (Discussion) against the particular local challenges. Finally, Section 5 (Conclusions) summarizes our findings and discusses relevant perspectives.

\section{Methodology}

\subsection{Study Area}

The study area was located at Petone and Alicetown, which is part of Hutt city near Wellington, New Zealand (Figure 1). The area was historically settled in the late 19th and early 20th centuries to the point where the floodplain of the adjoining Hutt River is now largely urbanized (Figure 1). The Petone area has been identified as the most vulnerable geographic unit within Hutt City Council, together with the reclaimed Seaview area, to the east of Petone [33]. Hutt city is protected from fluvial flooding by one of New Zealand's most comprehensive flood protection schemes on the Hutt River [34]. Paulik $[10,35]$ have shown that the wider Wellington region (including Hutt City) has some of the highest pipeline exposure to rising coastal hazards and accordingly some of the highest associated replacement costs of water infrastructure in New Zealand. In New Zealand, SLR is the primary driver of coastal flooding. Storm surges and waves are secondary. Such exposure is attributed to ongoing SLR, which is the primary driver of coastal flood with coastal storm intensity, storm surges, and wave 
secondary drivers. However, locally for the study area, more intense southerly winds could exacerbate the depth and frequency of coastal flooding. Nevertheless, in relation to the network performance and the option of retreat, local water managers are primarily concerned with ongoing sea level rise and the thresholds for network performance.

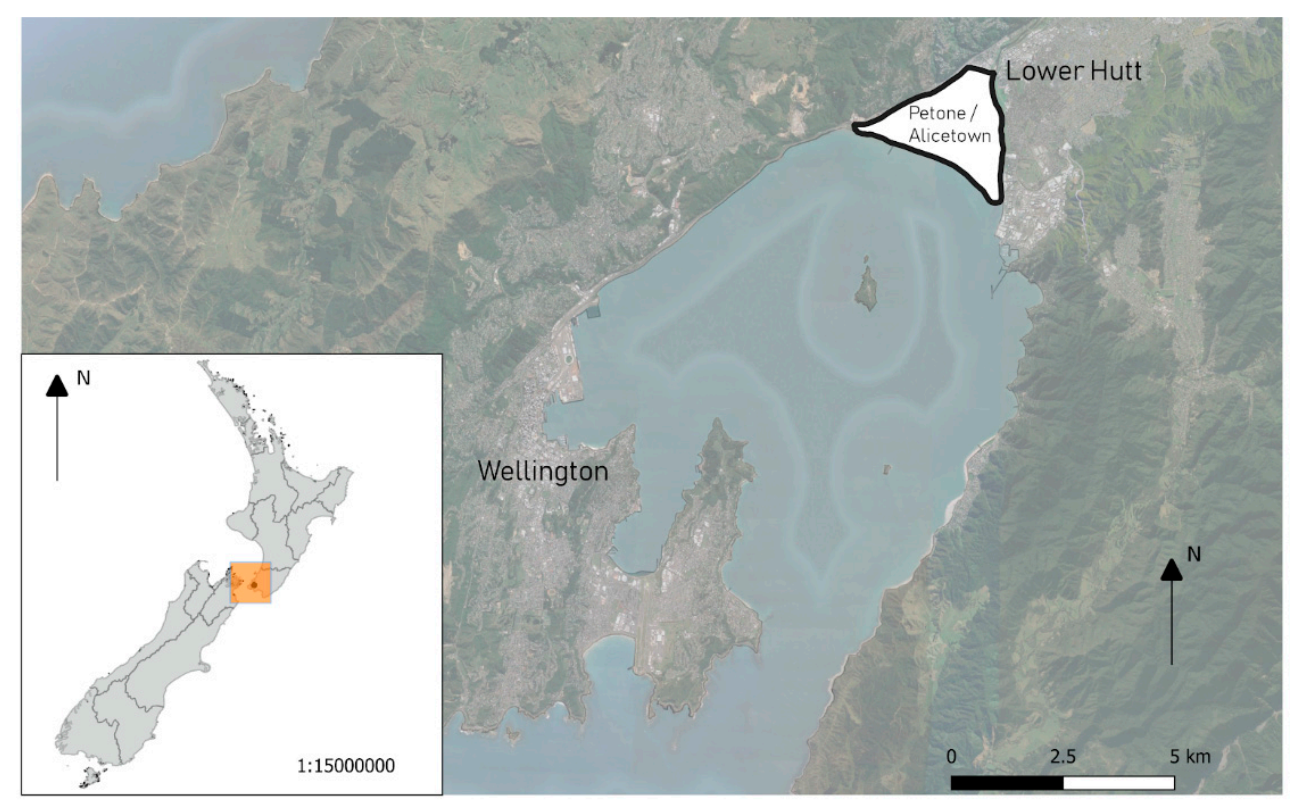

Figure 1. Study Area in Hutt City, Wellington region New Zealand.

The study area is serviced mostly by a gravity-based drainage system. Discharge points of such drainage systems are often located at the lowest elevation points of populated areas to maximize hydraulic heads [36]. Therefore, changes in tail water level as a result of SLR have a considerable impact on the hydraulic discharge capacity of the system. Figure 2 shows a cross section of the elevation and gravity-based drainage system in the study area.

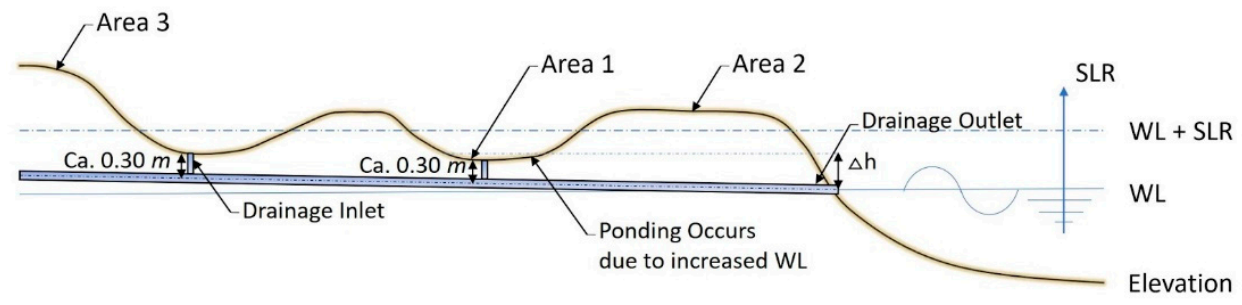

Figure 2. Conceptual cross section of the two-waters network in Petone. "WL" = water level, "SLR" = sea level rise, and " $\mathrm{h}$ " $=$ the elevation difference of the drainage system.

\subsection{Dynamic Adaptive Policy Pathways (DAPP)}

The DAPP approach (a comprehensive description may be found in [27]) aims to facilitate decision-making under deep uncertainty [37] and is well suited for planning infrastructure and community development over time under changing climate risk conditions. DAPP is designed to accommodate a range of options and to allow alternative future pathways to be explored, accounting for uncertainties and changes over time, i.e., to reflect that policy actions have an uncertain design life and may become ineffective sooner or later as boundary conditions change [38]. The DAPP approach is adopted in the New Zealand national coastal hazards and climate change guidelines $[8,26]$ with the aim of moving practice from static and time-bound planning to dynamic decision making that enables adjustments over time without creating lock-in of policy decisions [26]. To facilitate this shift in practice 
to implementable decisions, stakeholders require an understanding of the implications of changing risk. Serious games [39] and collaborative decision-making panels have been used for this purpose [40]. Pathway shifts occur when it is clear that the current management will fail to meet the objectives of the strategy, i.e., an adaptation threshold (AT). Before such a threshold is reached, there will be early signals (Figure 3 ) that planning for another adaptation option (i.e., a pathway that can reach the required service performance levels) should be initiated [38]. For example, emerging impacts of SLR often reach social coping capacities before damaging physical thresholds are reached [41].

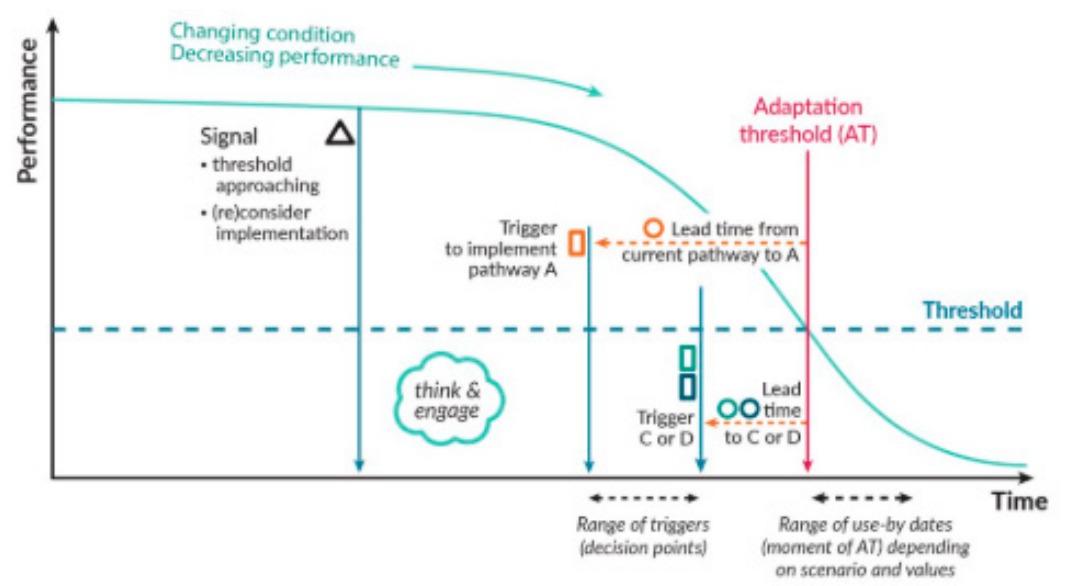

Figure 3. Reduction of service level over time, illustrating an adaptation threshold (AT), signals, and triggers. Source: Ministry for the Environment, 2017 [8] as adapted from graphic by Marjolijn Haasnoot, Deltares and the University of Utrecht, the Netherlands.

ATs are defined as the thresholds where boundary conditions are exceeded due to an increasing severity or disruptiveness of the hazard, requiring new actions to ensure acceptable performance levels (Figure 3). Thresholds can be identified using technical, environmental, societal, or economic indicators $[30,38]$. An AT is found by modelling the system and placing it under increasingly larger stress [42]. ATs can also be identified through moderated processes using scenarios with different conditions representing stress and using sensitivity testing. After a continuing decrease of asset performance due to changing environmental and climatic conditions, a trigger (decision point) is reached to implement the next option or action along the pre-agreed or a different adaptive pathway. The trigger needs to build in an implementation window (lead time), appropriate to the next option, to ensure the performance of the network does not drop under the pre-agreed AT.

\subsection{Methodological Framework}

The methodological framework used to develop our prototype is shown in Figure 4. First, drainage system thresholds were identified and adaptation portfolios were developed with their associated thresholds, aligned with the development of area-specific retreat strategies. These elements were elicited through a workshop organized with a group of local experts across different functions and professions from the agencies responsible for water infrastructure, land use planning, and asset management, which were specifically aimed at investigating possible adaptation options and drainage system thresholds. For drainage system ATs, the vulnerability of stormwater and wastewater assets to SLR were assessed by: (a) the number of exposed infrastructure assets; (b) how they are affected; (c) at which SLR increment they are affected; (d) and at which spatial location within the study area and in each of the storm and wastewater networks this occurs. The key elements are elaborated in Figure 4. 


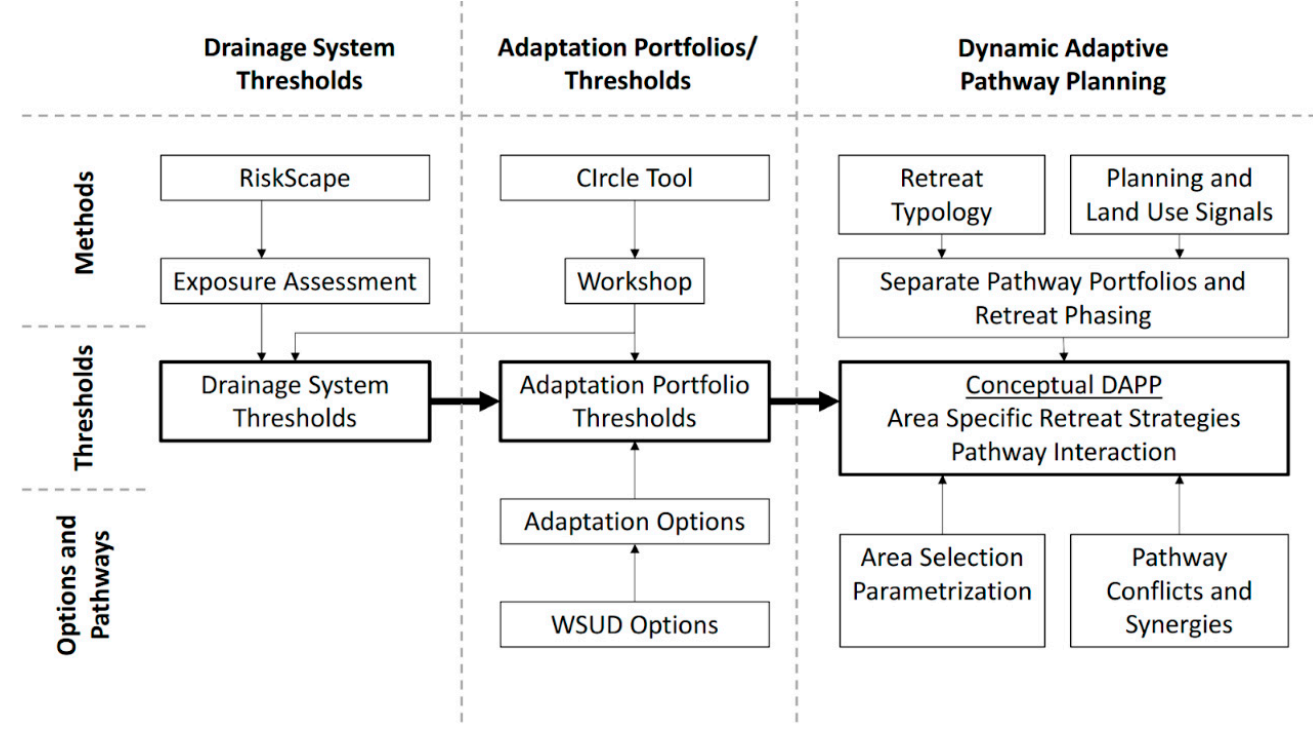

Figure 4. Methodological framework. "WSUD" = "Water Sensitive Urban Design", "DAPP" = "Dynamic Adaptive Policy Pathways". Both concepts and "RiskScape" and "Circle Tool" methods are explained in the text.

\subsubsection{Knowledge Co-Production Process}

The workshop was comprised of a systematic optioneering process where the practitioners (see Section 2.3) co-identified system thresholds and pathways (available options and option lead times) for a managed retreat of the stormwater and wastewater infrastructure. To identify interdependencies and cascading effects and to represent different perspectives, the circle tool was used. The circle tool (critical infrastructure: relations and consequences for life and environment) — developed at Deltares, the Netherlands-was used to facilitate analysis and visualization of cascading effects on infrastructure networks. It may be used to create awareness of risk to critical infrastructure under hazard conditions including from climate change effects [43]. It does so by dividing critical infrastructure into different categories, with the ability to add direct effects and establish interdependencies and cascading effects, between the different categories under stress (e.g., overland drainage flow, stormwater network, and wastewater pumps, dikes).

\subsubsection{Stormwater and Wastewater System Thresholds}

Adaptation thresholds for stormwater and wastewater system were determined from the combined output of a (spatial) exposure assessment and were co-developed with water managers and practitioners through the workshop using a mix of quantitative and qualitative threshold indicators. The indicators denote limits when the current system performance is unacceptable and/or unsustainable, for example, "x cm" of SLR (quantitative) or "community tolerability" of impact (qualitative). The thresholds was comprised of physical consequences such as increasing wastewater overflows, regular ponding due to raised groundwater levels, and regular overflows to properties or watercourses. Based on the input from the workshop, SLR was found to be the most critical hazard for defining thresholds in this study.

To assess the spatial risk exposure of assets in the study area, hazard data layers for the present-day $1 \%$ annual exceedance probabilities (AEP) of coastal flood water levels combined with $0.1 \mathrm{~m}$ increments of SLR (relative to present mean sea level) [10] were used. In this dataset, the coastal-flood level was comprised of storm-tide and wave setup water level in Wellington Harbor (Figure 1) [10]. These derived hazard layers were overlain with selected infrastructure asset data layers, comprised of polyline and point data that determined the spatial exposure to coastal flood hazards. SLR increment overlays were mapped onto asset layers for exposure up to +1.2 m SLR using RiskScape [10]. RiskScape is a decision-support and visualization tool that combines the three layers from a Hazard Module, 
a Vulnerability Module, and an Asset Module [44] to generate a spatial realization of exposed assets at risk from infrequent coastal-flood events for SLR (hazard) increments in the study area. RiskScape has been used to map flood exposure on a nation-wide scale in New Zealand [10] and was therefore used in this research for consistency.

From the exposure assessment and following recommendations from the stakeholder workshop, quantitative thresholds were identified at $0.3 \mathrm{~m}, 0.4 \mathrm{~m}, 0.5 \mathrm{~m}$, and $0.8 \mathrm{~m}$ of SLR increments, respectively, for different assets in different subareas. Based on these increments, a prototype of the expected pathway scenario-based lifetimes and failure conditions was generated. The $0.3 \mathrm{~m}$ SLR threshold was associated with the limits of the gravity-based drainage system and regular ponding due to increases in ground water levels. The $0.4 \mathrm{~m}$ and $0.5 \mathrm{~m}$ thresholds were associated with the wastewater pumps becoming increasingly exposed to flooding by the time $0.5 \mathrm{~m}$ SLR was reached. Moreover, there was a major increase in the number of manholes and sumps exposed. Beyond $0.8 \mathrm{~m}$, the number of assets affected by increasing SLR tailed off. This means that the biggest stresses on the stormwater and wastewater system occurred in the first $0.8 \mathrm{~m}$ of SLR increments. The qualitative thresholds were related to observed unacceptable performance from a community and from a service provider perspective.

\subsubsection{Adaptation Portfolios/Thresholds}

Adaptation portfolios were developed in order to create pathways that would avoid reaching ATs. Due to the complexity of the local drainage system and the importance of the effective implementation of a range of adaptations to the different parts of the drainage network, ATs were developed for each adaptation portfolio. Associated signals for land use and pathway changes were also identified. Individual thresholds were determined for each adaptation option based on the conditions when their Level of Service becomes unacceptable (failure conditions). The list of possible adaptation options was then simplified into portfolios of pathways that combined would achieve the objectives. The failure conditions are shown in Figure 5 and are based on the type of option and the system thresholds which were determined by portfolio, rather than by portfolio in each subarea. However, within each area, different portfolios have pathway options with different failure conditions. For example, Portfolio 5 (see Figure 5) would not be applicable in Area 1 because the pump inundation at lower SLR would start to pump saltwater into the system and stop the pumps working. Incrementally increasing the pump capacity would not address salinization.

ATs for retreating stormwater and wastewater infrastructure varied over the study area (e.g., due to topography). This means area specific retreat strategies had to be developed. This was done by dividing the total study area into subareas (defined by their elevation and the degree of asset exposure as a function of SLR increments). Adaptation options to build pathway portfolios were initially based on the scientific literature and through expert input from stakeholders, responsible agencies, and analyzed by the authors. These were then systematically tailored into a portfolio of pathway of adaptation options at each subarea. Adaptation options in pathway portfolios were finally divided in different adaptation strategies, all aimed at maintaining service levels and avoiding an AT. We assume that, depending on the retreat thresholds for a subarea, these different portfolios maintain service until this threshold is reached. We included water-sensitive urban design (WSUD) options in the portfolios to illustrate whether these could extend ATs in time for the retreat strategy. For example, by increasing capacity and delaying entrance of stormwater water and wastewater to the drainage system during an extreme event by temporarily storing stormwater or by facilitating local infiltration until the system normalizes again. WSUD options generally offer a reduction in peak flow that can extend the use of traditional grey infrastructure in the system [20] and maintain service levels in a cost-effective manner. Siekmann and Siekmann [45] describes WSUD as the intensified use of surface detention and suggests that disconnecting drained areas is a first step in preparing drainage systems for climate change impacts by creating a measure that is easier to upgrade than traditional sewer systems, due to their higher adaptive capacity and for extending the retreat threshold in adjacent areas. We therefore used WSUD in the repurposing stage of a subarea. 


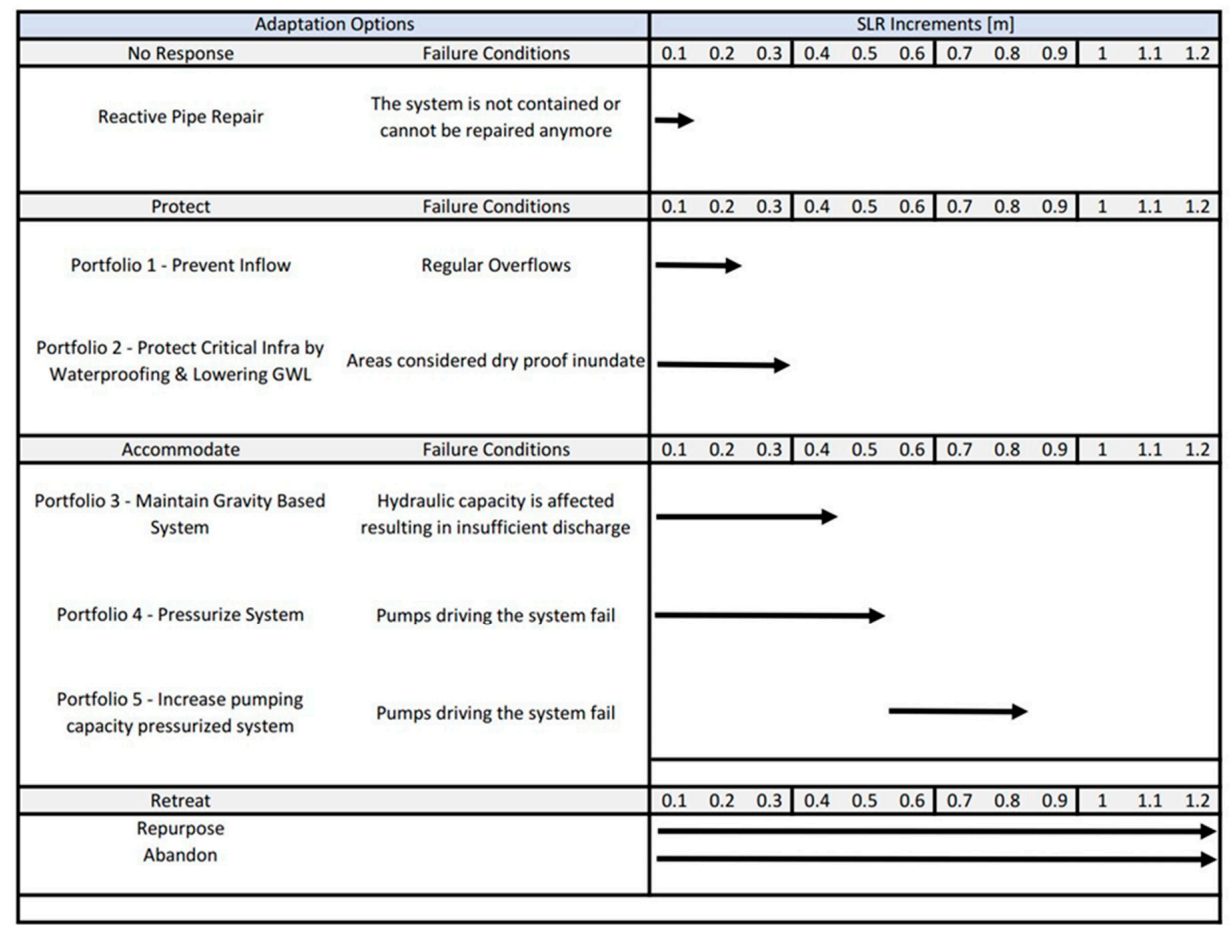

Figure 5. Adaptation portfolios and adaptation thresholds in terms of sea level rise (SLR) increments. ("GWL" = ground water level).

\subsubsection{Dynamic Adaptive Pathway Planning}

In order to choose a retreat approach for the infrastructure, a typology, or sequence of retreat phases, was assumed. Here, we adopted the typology outlined in Olufson [46] as the basis for planning a long-term managed retreat strategy, by sequencing options and actions. The typology retreat phases used were as follows: Community Engagement (1), Planning and Preparing (2), Enabling Investment (3), Active Retreat and Infrastructure Relocation (4), and Clean-up and Land Rehabilitation/Repurposing (5). Planning and land use change signals.

The role that statutory planning and design codes can play in signaling land use constraints or change (as options) within the retreat strategy were added to the adaptation portfolios in preparation for retreat phasing. Adaptation options were unique for each subarea. Material from Tables 25 and 26 found in the New Zealand national coastal hazards and climate change guidelines [8] were used and illustrate possible statutory and non-statutory planning processes, methods, and techniques that can be used alongside the water infrastructure retreat to signal upcoming changes needed for the next retreat stage [46]. These include conditional rules and specifications for new development: (1) limiting development in the retreat area by applying plan and rule changes; (2) restricting development in the retreat area (in anticipation of a retreat); (3) relocating and preparing the retreat area for a new function; and (4) rezoning for repurposing land use.

Lastly, by iterating to determine the strategy for each of the subareas and populating them with possible portfolios, a conceptual DAPP was formed and used to illustrate how a retreat could be staged. The DAPP framework we used integrates all of the abovementioned elements, i.e., the drainage system thresholds, adaptation portfolios/thresholds, subarea characteristics, and retreat typology. This enabled us to investigate the interactions between different subareas systematically and to identify opportunities for buying time, during which planning and preparatory work can be undertaken to support the active retreat stage. 


\section{Results}

Based on the methodology outlined in Figure 4, a prototype decision-making framework, implementing a dynamic and adaptive spatial sequencing for retreat and Levels of Service for stormwater and wastewater, was developed. As the sea-level rises, ponding of pluvial rainfall in combination with groundwater tables rising to ATs makes other traditional hard and soft adaptations ineffective, except where there are local opportunities to use water sensitive design to delay retreat in smaller sub areas as shown in Figure 6. We also identified individual subareas that could contribute to a managed retreat strategy in the whole study area, for example by making a spatial shift in retreat phasing within the smaller subareas, each having their own unique retreat strategy.

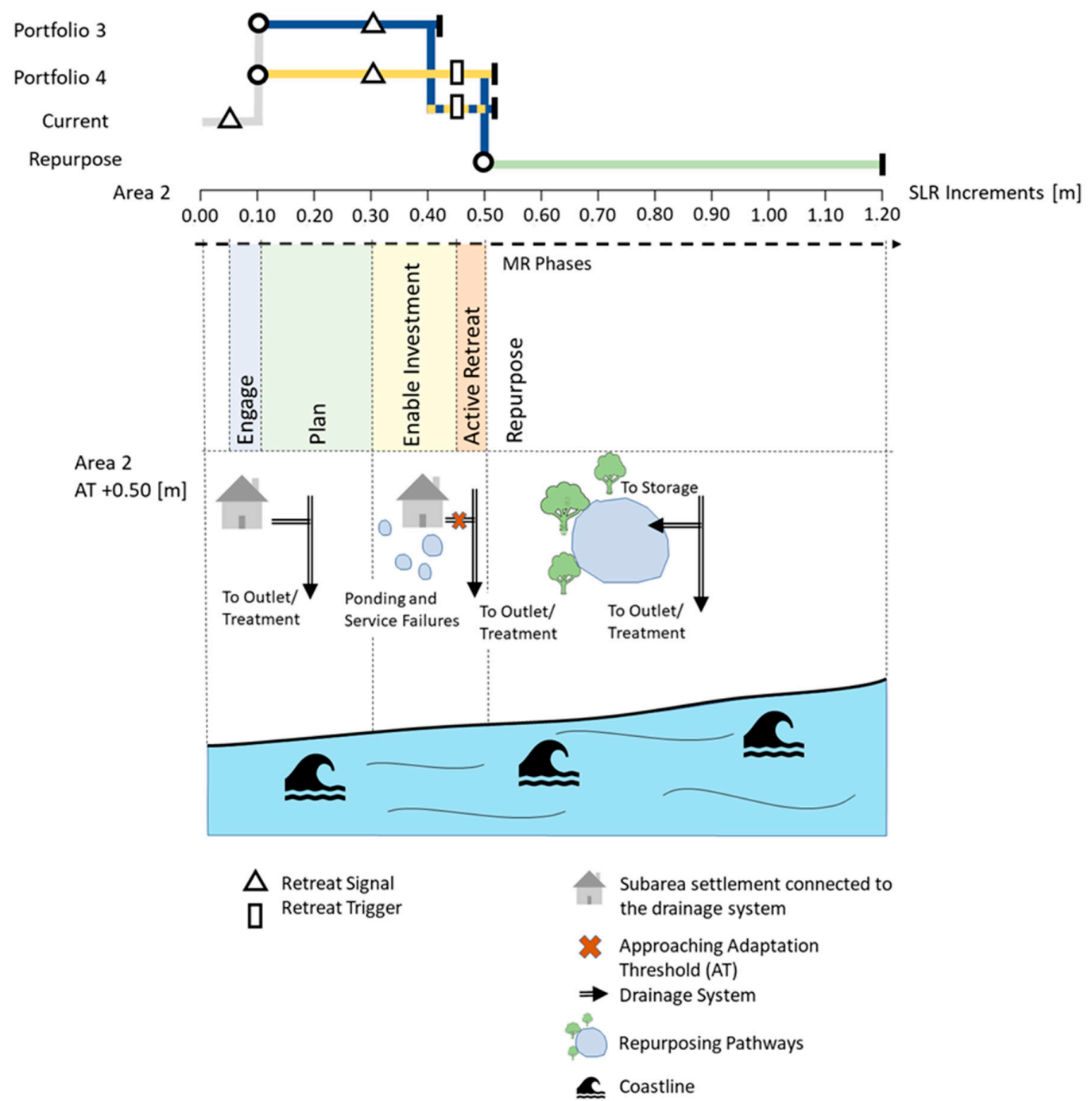

Figure 6. Schematic DAPP for subarea 2. Note: MR is managed retreat, AT = adaptation threshold, SLR = sea-level rise.

Figure 6 shows an illustrative schematic of the resulting DAPP for subarea 2. Signals (warning) and triggers (decision points) were identified for each of the strategies used in the different subareas. For some pathways, multiple signals were associated with the same pathway sequence. Signals indicated a change in the retreat stage and triggers marked the start of active retreat steps. Here, signals were defined qualitatively, based on the knowledge co-production in Section 2.3.1. The different triggers were linked to a mix of quantitative and qualitative ATs established across the study area. 
Table 1 summarizes the parameters identified for each of the subareas and used by our prototype (e.g., system retreat thresholds and considered portfolios). The retreat threshold for subarea 3 was the highest, indicating that this area was the most relevant for consideration of more long-term portfolios. This was mainly due to emergent asset exposure only being triggered at higher SLR increments. Subarea 1 had the lowest AT and the highest asset exposure out of all SLR increments (including critical infrastructure), which was related to both high occurrences of (critical) assets and low-lying land. Arguably, the sequenced process/portfolio for pre-emptive managed retreat from this subarea could commence soon. The intermediate subarea 2, located closest to the coastline, had a high intensification of asset exposure. Even so, subarea 2 had a higher elevation than subarea 1 and hence an increased system retreat threshold, making it a good candidate to be considered for more transformative portfolios.

Table 1. DAPP properties for each subarea.

\begin{tabular}{cccc}
\hline & Subarea 1 & Subarea 2 & Subarea 3 \\
\hline System Retreat Threshold [m] & 0.30 & 0.50 & 0.80 \\
\hline Portfolios considered & 1,2 & 3,4 & $3,4,5$ \\
\hline $\begin{array}{c}\text { Asset exposure intensification } \\
\text { (Figure S1) }\end{array}$ & Intensification & Intensification & Intensification at higher SLR increments \\
\hline
\end{tabular}

(1) Conditional rules and specifications for new development

(2) Limiting development in the retreat area

Planning and Land use Signals

(3) Restricting development in the retreat area

(4) Relocating and preparing the retreat area repurposing

(5) Rezoning for repurposing

\begin{tabular}{|c|c|c|c|}
\hline \multicolumn{4}{|c|}{$\begin{array}{l}\text { Thresholds from New Zealand } \\
\quad \text { climate projections }{ }^{1}\end{array}$} \\
\hline NZ RCP $2.6 \mathrm{M}$ & Ca. 2070 & Ca. 2110 & - \\
\hline NZ RCP $4.5 \mathrm{M}$ & Ca. 2060 & Ca. 2090 & Ca. 2140 \\
\hline NZ RCP $8.5 \mathrm{M}$ & Ca. 2050 & Ca. 2075 & Ca. 2100 \\
\hline NZ RCP $8.5 \mathrm{H}+$ & Ca. 2045 & Ca. 2060 & Ca. 2085 \\
\hline
\end{tabular}

${ }^{1}$ Use the 4 representative concentration pathway (RCP) scenarios in the Coastal Hazards and Climate Change Guidance [8] (Figure 27 and Table 11 in reference [8] to derive approximate decades for specific SLR thresholds. Figure $\mathrm{S} 1$ is in the Supplementary Information.

\subsection{Pathway Conflicts and Synergies}

The parallel implementation of pathway portfolios for each area and the interaction between the portfolios, when implemented, provides an opportunity to create synergies between the different options across the whole study area. The possibility of having a visual overview between the different portfolios and pathways in each of the three areas enables the system to be adjusted, using a range of different adaptation strategies and to achieve a cohesive and well-managed retreat. For example, implementation strategies in the higher elevated part of the study area enable discharge reductions in the low-lying parts. This results in lower requirements for adaptation or buys extra time before an option or pathway in another area has to be changed. The increased flexibility to influence one area by implementing complementary adaptation options in different areas is likely to be crucial for buying time in this case across the entire study area drainage system, i.e., for robust planning and costing of the adaptation options and the engineering design undertaken for the active retreat phases.

A conceptual way of illustrating the interaction between different pathways in different areas provides an overall dynamic strategy for the area (Figure 7). All areas will need to retreat eventually with ongoing SLR, but sequencing can be different and thus the options provide flexibility depending how the change progresses. The synergies and conflicts between pathways in different areas are marked with the arrows showing Synergies $(+)$ and Conflicts $(-)$. The protype portfolios first started with a DAPP for each of the subareas across the study area. The thresholds identified for the study area were added to the $x$-axis, indicating the need for pathway changes for the current drainage 
system. For the areas identified for managed retreat, retreat phases were also indicated along the $x$-axis of the DAPP. Aligning these pathways for each of the areas allowed for the visualization of interaction between different areas. This enabled positive and negative feedbacks to be illustrated between different options and pathway strategies, depending on the phase of the retreat. For example, initial stages of retreat could create redundancy in the system by leaving pipes in the ground, but not have the extra discharge from residential/commercial use. This in turn might offer a positive effect on the rest of the drainage system. Over time, the capacity of this system will decrease, so we assume that it will not be upgraded indefinitely, as there will be a retreat when conditions reach the trigger (decision point), and there is little benefit from doing so. During repurposing, however, retention space could be created to allow for increased water storage capacity that could have amenity and recreational value for the remaining and wider community beyond the study area. This also could have a positive effect on the pathways implemented for the other sub areas.

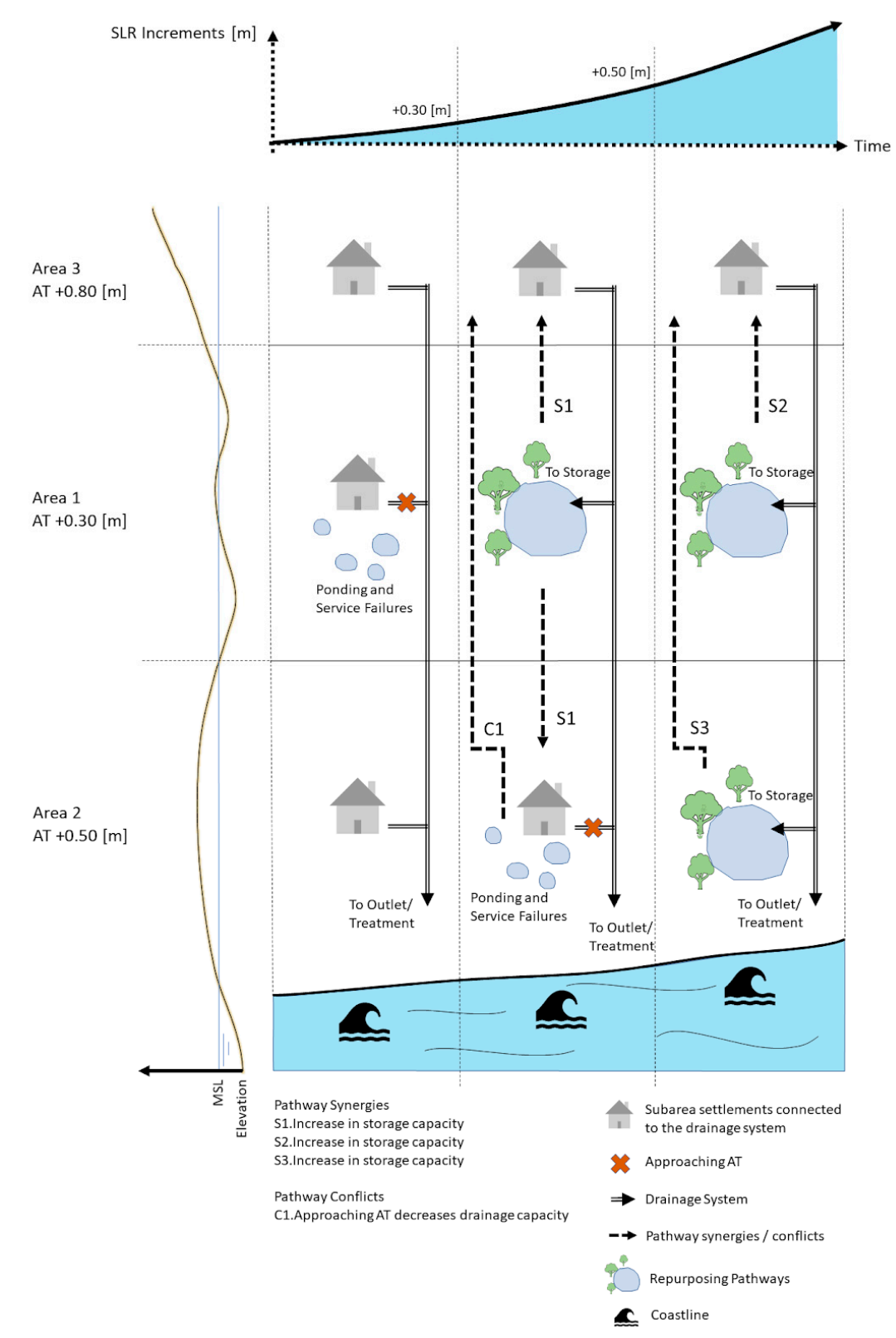

Figure 7. Schematic of the prototype DAPP portfolios for each subarea and their spatial and temporal interconnections, as the pre-agreed AT in each subarea is reached. The profile of land elevation on the left is a simplified version of Figure 2. 


\subsection{Prototype for Decision-Making}

Combining the analytical elements discussed above yields a novel prototype framework for decision-making and outlines a systematic 'routine' (Figure 8) that provides critical insights on how water infrastructure can be retreated in the face of ongoing SLR. The structure of the decision-making framework has three steps:

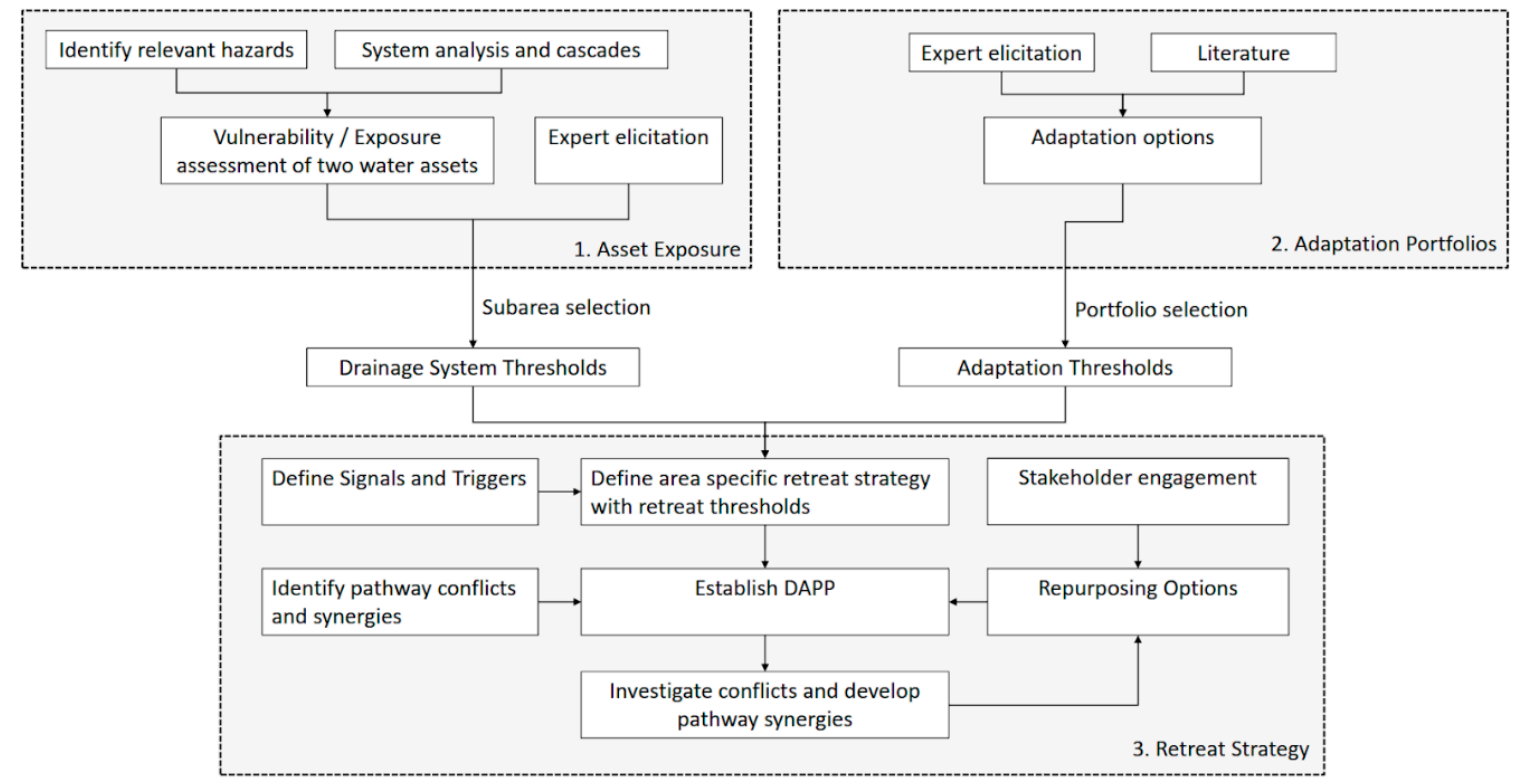

Figure 8. Decision-tree 'routine' for managing the retreat process for network infrastructure.

Step 1. Identify the area concerned using cross sections (as in Figure 2) together with information on asset exposure and their intensification as a function of SLR increments (Supplementary Information). This is done based on drainage system thresholds (defined at subarea levels) using the following parameters: asset exposure and intensification, elevation classification (DEM), pumping station exposure, coastline proximity, and area opportunities.

Step 2. Develop pathways through co-production with practitioners and water managers that utilizes adaptation options for stormwater and wastewater infrastructure to maintain services until the retreat adaptation threshold of a subarea is reached. Then, group adaptation options into pathway portfolios with associated thresholds.

Step 3. Use the coincidence and parallel implementation between the area specific options and pathways to enable the spatial retreat of services in a managed way. Pathway conflicts and synergies can be investigated to identify interactions between subareas to aid the spatial retreat of services. Repurposing options can be considered for increasing drainage capacity (and creating amenity), which can extend services in adjacent areas.

By following these three steps, area specific adaptations can be implemented using their inter-relationships to derive a cohesive managed retreat strategy. Planning signals can also be added to the pathways to help initiate the planning process, measures, and methods. Such pathway changes will be necessary to facilitate community retreat in a parallel process. The planning signals are not related to different portfolios of options for each area but rather to the retreat phase where the portfolios are based. When used as part of the described 'routine', pathway conflicts can be identified another iteration made to either redefine pathways or create measures mitigating the effects of these conflicts.

Along all steps, it is critically important to involve relevant stakeholders, both for validation and for contributing to the steps taken to help identify coping thresholds that are relevant to the particular community. Local expert knowledge combined with community input can minimize chances 
of critical aspects being overlooked, embedding community understanding and developing 'buy-in' to the strategy, and thus aiding implementation.

\section{Discussion}

Our research demonstrates whether and how a preemptive managed retreat strategy can be developed for stormwater and wastewater infrastructure as an adaptation to SLR. Relevant exposure and vulnerability information for developing a systematic managed retreat strategy was collected and integrated into a novel decision-making framework using a managed retreat typology of retreat components by using a DAPP approach to identify and assess specific options and pathways for the study area. Our study shows how a managed retreat strategy can be implemented over time in different topographic settings. The results of this research can be used by the responsible agencies to facilitate engagement with the local community and to gain buy-in for planned retreat of water services that creates the least disruption to the community and the available investment streams.

\subsection{Levels of Service}

The duration of services or how long stormwater and wastewater services can be maintained depends on the characteristics of the retreat phase within the overall retreat strategy of the retreat area. Active retreat should be initiated before the AT of the next option in the portfolio pathway is reached. This is facilitated by signals like planning provisions to warn and condition-based triggers to decide on options and pathways ahead of the threshold. As illustrated in Figure 7, this provides a conceptual DAPP that can set out portfolio-specific conditions using SLR increments, thus enabling the different portfolios to be implemented. The duration and Levels of Service depends on the area strategy that is set when developing the retreat sequencing. Not switching to alternative portfolios before an AT is reached may result in steep cost increases as economic damage and disruption increases, an inability to adapt the current system, and the system being no longer contained. Monitoring pathway performance enables timely signals and triggers to be implemented that warn of an approaching AT, and thus minimizes economic and community disruption. Not implementing signals and triggers results in a reduced ability or compressed timeframe to switch portfolios before reaching an AT and preclude the possibility of signaling these upcoming changes to the community.

The stakeholder workshop highlighted the need in any retreat strategy for the coping capacity of the community to form an integral part of identifying the signals and triggers. When the coping capacity of the community is lower than the technical threshold (e.g., while the system is technically and design-wise able to cope with increased periodic overflows), the community impact may be unacceptable and/or unsustainable, potentially bringing the ATs forward or could extend the duration of pathways [32]. Consideration of coping capacity without direct involvement of local stakeholders could result in a loss of community support and potential legal challenges [47] from local stakeholders having to cope with more frequent flooding, including cumulative nuisance inundation, above their tolerance limits. This highlights the centrality of stakeholder and community engagement in managed retreat planning and decision making.

\subsection{Measures and Pathways}

Adaptation options and pathways were developed based on relevant technical and scientific literature, expert elicitation, complemented by an analysis of the drainage system, including its hazard exposure and topographic setting. Ideally, a unique set of pathway portfolios could have been developed for each of the different retreat subareas to reflect that different adaptation pathways are likely to perform differently in each subarea.

The proposed approach for implementing area-dependent retreat strategies essentially 'buys time' for residents to manage their own retreat from the area and for authorities to stage their retreat expenditure more gradually. That said, this could potentially create unrealistic expectations for residents in areas that are retreated at larger ATs. Thus, the extra time might alleviate the "pressure" of 
the eventual move and create a false sense of security under current conditions. Meanwhile, property values are likely to be detrimentally affected over time, depending on how the retreat is signaled and funded [48]. There is also a reputational and legal risk for the water agency and the council if they claim that water services can be provided until a defined SLR increment, and then, due to a sudden disruptive event, this turns out to be unfeasible. At the time of this study, multiple service failures had occurred nearby in Wellington City, signaling vulnerability in the drainage systems regionally. Similar evidence can be drawn from the Matatā case in New Zealand [49], where a community was able to rebuild in the same place after a mud-debris slide some years earlier after receiving disaster funding and building consents, only to find later that the protection measures proposed were unfeasible. A managed retreat strategy is now being implemented which is the subject of a legal challenge from the community.

Signaling planning and land use changes early to the community and relevant stakeholders can enable changes in retreat phases and service levels to be anticipated. Currently, there is a signal provided in the study area by the Regional Standard for Water Services implemented by the water agency, which requires raised floor levels for new developments to accommodate future sea levels. This is based on the SLR increment projections in the national coastal hazards and climate change guidance (Tables 10 and 11 found in [8]) for future SLR impacts. However, such signals could create a legacy effect for managing the drainage system because the dwellings are being accommodated at a higher threshold than the infrastructure servicing it and adjacent properties. This in turn could create disruption where part of the community potentially wants to extend the service in the accommodated area, creating conflicts for the retreat strategy in adjacent areas and limiting repurposing possibilities by forcing expensive maintenance of services as drainage conditions become worse. Other signals are in place in the study area through the district plan highlighting hazard risks and through insurance which is unavailable for some hazard risks for new buildings and additional footprints of existing buildings.

\subsection{Sequencing and Withdrawal}

The retreat typology is based on a signaling approach where the community starts to withdraw as part of a planned proactive retreat strategy. Alternatively, the council could start to withdraw services. Some councils in New Zealand have signaled that service levels for infrastructure will be reduced or some services will not be provided anymore as coastal inundation becomes more frequent ( $\mathrm{D}$ and $\mathrm{C}$ Gallagher v Tasman District Council, NZ Environment Court W245/2014). Following the managed retreat typology outlined in Olufson [46] and the lessons learned in Lawrence et al. [24], buy-outs or compensation could initiate house relocation or removal before a service level change is signaled. In a post-disaster scenario, where service levels are compromised, community retreat often occurs as a reactive response [50]. If there is a decision to lead with infrastructure retreat, part of the community might choose to stay and accept the reduction in Levels of Service. In the study area this could hinder repurposing options for the retreated subareas, thereby precluding the creation of recreational or ecological amenity for the community and disrupt retreat of adjacent subareas. This would accelerate the onset of SLR ATs for retreat in those areas.

\subsection{Considerations for Managed Retreat Strategy Development}

New Zealand's first National Climate Risk Assessment [51] identified the provision of water services to the built environment as one of the top 10 climate change risks. Water managers in New Zealand are currently planning infrastructure renewal, which will involve very large investments in the order of billions of dollars $[13,14]$. These will require consideration of the impacts of SLR compounded by increases in heavy rainfall and coastal flooding, and be adjustable within the lifetime of the infrastructure. As such, the research on a DAPP prototype presented in this paper is both impactful and very timely.

Further methodological considerations should be developed in order to go beyond the current prototype. The first consideration relates to the use of DAPP signals and triggers in conjunction with planning/land use measures, retreat signals, and triggers. Implementing DAPP signals and triggers for 
monitoring of pathway/portfolio lead times could enable a more detailed pathways assessment to be undertaken. Quantification of service duration and Levels of Service based on full scale hydraulic analyses would enable a more detailed assessment of the conditions under which pathways have to be changed to maintain service levels for a community. This would provide a more complete basis for discussion with a community and the local council. Involving the community and other stakeholders in investigating what they currently perceive as unacceptable disruption (threshold conditions) could inform retreat decisions, and what their changing expectations might be in terms of Levels of Service. This would aid future decision-making and help to gain greater consensus on ATs.

The second consideration relates to the costing of the adaptation portfolios. Assessing the costs and benefits of the different pathway options indicate how managed retreat expenditure could be staged over the lifetime of the different options within portfolio pathways. There will be an inflexion point where maintaining the system to keep up Levels of Service becomes unsustainable economically and/or with public health and safety considerations. These will influence both the retreat phasing and ATs for the retreat portfolios. Showing the staging of costs between the current reactive approach and a proactive long-term retreat approach would enable the agencies to consider a change in strategy that allows for smoothing of budget allocations over the lifetime of the investments needed for retreat of the water infrastructure. This would reduce the disruption of sudden large costs associated with the current reactive modes of decision making.

Finally, there is the matter of how a managed retreat strategy can be communicated to the community and the involvement of the community in the managed retreat process. Water infrastructure provides services to communities and as such, adaptation to these services is not purely a technical issue [22]. It has equity, financial, and political implications that are non-trivial for the community, stakeholders, and agencies. Community-relevant issues have been included into the prototype by signaling planning and land use considerations early in the retreat stages by highlighting possible amenity benefits that can 'buy time' for preparation before the active retreat stage starts and by identifying the need for community engagement in developing the related signals, triggers, and adaptation thresholds. Community involvement is critical for gaining support and the momentum needed to start systematically implementing the step changes over a long-term planning horizon. This can help to avoid higher levels of disruption from reactive adaptation and lower the cost of addressing the damage from sea-level rise hazards.

\section{Conclusions}

This paper demonstrates how a systematic and adaptive approach to frame retreat in different areas can address the deep uncertainties arising from SLR when implementing a stormwater and wastewater retreat strategy. This enables better understanding and visualization of how a retreat of water infrastructure could be implemented across a community. This is made possible using a combination of: (1) an area specific retreat strategy; (2) area specific pathways; (3) area specific retreat phases; (4) land use change signals; and (5) by identifying pathway conflicts and synergies. Considering adaptation thresholds of $+0.3 \mathrm{~m},(+0.4)+0.5 \mathrm{~m}$, and $+0.8 \mathrm{~m}$ alongside community-based signals and triggers, different suites of actions, land use planning implications, and failure conditions are identified, and associated pathway portfolios developed. The prototype that emerges provides a comprehensive framework for visualizing and managing the retreat of water infrastructure where coastal communities face similar hazards and may potentially help garner community understanding and 'buy-in' to the managed retreat adaptation option.

To the authors' knowledge, this is the first study to develop a framework for preemptive stormwater and wastewater infrastructure retreat where ongoing SLR is the primary driver. For the study area, adaptation decisions will need to be made collectively by the water agency and the local council with their communities. This includes whether to continue along the current pathway of reactive maintenance-i.e., to repair and accept major economic damages and community disruption with ad hoc and improvised solutions—or whether to embrace a pre-emptive approach where adaptation 
to SLR is undertaken in a more cost-effective and systematic manner with less overall disruption. The DAPP provides a framework for conceptualizing and organizing how to move from reactive decision making, to a more proactive and anticipatory mode of decision making that can include managed retreat in the planning process. The DAPP can also encompass a consideration of the many implementation issues such as funding and equitable compensation, planning of land use changes by signaling these early so as to minimize disruption, and enabling the creation of amenities by repurposing retreated areas.

Supplementary Materials: The following are available online at http://www.mdpi.com/2412-3811/5/11/92/s1, Figure S1: Location of asset exposure intensification at a current $1 \%$ AEP event.

Author Contributions: Conceptualization, R.B., J.L., and R.K.; methodology, R.K.; software, R.K.; validation, R.K., J.L.; formal analysis, R.K.; investigation, R.K.; resources, R.K., J.L.; data curation, R.K.; writing-original draft preparation, R.K.; writing-review and editing, R.K., J.L., R.B., and M.D.; visualization, R.K.; supervision, J.L., R.B., and M.D.; project administration, J.L.; funding acquisition, J.L. All authors have read and agreed to the published version of the manuscript.

Funding: This research was funded by the New Zealand Ministry of Business, Employment and Innovation (MBIE) through the Resilience Science Challenge Coastal Sub-theme "Adapting to New Zealand's Dynamic Coastal Hazards".

Acknowledgments: The authors would like to thank the following organizations and people. Wellington Water for providing data and engaging in the project, in particular Ben Fountain and Fraser Clark; NIWA for their support with the RiskScape tool, in particular Ben Popovich and Ryan Paulik; Hutt city for organizing the workshop and participating in it, in particular David Burt and Jörn Scherzer and to Sharon Westlake and Iain Dawe from Wellington Regional Council for their participation in the workshop.

Conflicts of Interest: The authors declare no conflict of interest.

\section{References}

1. Hinkel, J.; Lincke, D.; Vafeidis, A.T.; Perrette, M.; Nicholls, R.J.; Tol, R.S.; Marzeion, B.; Fettweis, X.; Ionescu, C.; Levermann, A. Coastal flood damage and adaptation costs under 21st century sea-level rise. Proc. Natl. Acad. Sci. USA 2014, 111, 3292-3297. [CrossRef] [PubMed]

2. Hinkel, J.; Aerts, J.C.; Brown, S.; Jiménez, J.A.; Lincke, D.; Nicholls, R.J.; Scussolini, P.; Sanchez-Arcilla, A.; Vafeidis, A.; Addo, K.A. The ability of societies to adapt to twenty-first-century sea-level rise. Nat. Clim. Chang. 2018, 8, 570-578. [CrossRef]

3. Kulp, S.A.; Strauss, B.H. New elevation data triple estimates of global vulnerability to sea-level rise and coastal flooding. Nat. Commun. 2019, 10, 1-12.

4. Brown, S.; Nicholls, R.J.; Goodwin, P.; Haigh, I.D.; Lincke, D.; Vafeidis, A.T.; Hinkel, J. Quantifying land and people exposed to sea-level rise with no mitigation and $1.5^{\circ} \mathrm{C}$ and $2.0^{\circ} \mathrm{C}$ rise in global temperatures to Year 2300. Earth's Future 2018, 6, 583-600. [CrossRef]

5. Oppenheimer, M.; Glavovic, B.; Hinkel, J.; van de Wal, R.; Magnan, A.; Abd-Elgawad, A. Chapter 4: Sea-level rise and implications for low-lying islands, coasts and communities. In IPCC Special Report on the Ocean and Cryosphere in a Changing Climate; Pörtner, H.O., Roberts, D., Masson-Delmotte, V., Zhai, P., Tignor, Y., Poloczanska, E., Eds.; Cambridge University Press: Cambridge, UK, 2019; Available online: https: //www.ipcc.ch/site/assets/uploads/sites/3/2019/11/08_SROCC_Ch04_FINAL.pdf (accessed on 20 July 2020).

6. Ranasinghe, R. Assessing climate change impacts on open sandy coasts: A review. Earth Sci. Rev. 2016, 160, 320-332. [CrossRef]

7. Vousdoukas, M.I.; Ranasinghe, R.; Mentaschi, L.; Plomaritis, T.A.; Athanasiou, P.; Luijendijk, A.; Feyen, L. Sandy coastlines under threat of erosion. Nat. Clim. Chang. 2020, 10, 260-263. [CrossRef]

8. Ministry for the Environment. Coastal Hazards and Climate Change: Guidance for Local Government; Bell, R.G., Lawrence, J., Allan, S., Blackett, P., Stephens, S.A., Eds.; Publication No. ME 1292; Ministry for the Environment: Wellington, New Zealand, 2017; 284p + Appendices. Available online: http://www.mfe.govt.nz/ sites/default/files/media/Climate\%20Change/coastal-hazards-guide-final.pdf (accessed on 1 October 2019).

9. Local Government New Zealand. The 2050 Challenge: Future Proofing our Communities; Local Government NZ: Wellington, New Zealand, 2016; Available online: http://www.lgnz.co.nz/assets/42597-LGNZ-2050Challenge-FinalWEB-small.pdf (accessed on 1 October 2019). 
10. Paulik, R.; Stephens, S.A.; Bell, R.G.; Wadhwa, S.; Popovich, B. National-scale built-environment exposure to 100-Year extreme sea levels and sea-level rise. Sustainability 2020, 12, 1513. [CrossRef]

11. Hughes, J.; Cowper-Heays, K.; Olesson, E.; Bell, R.; Stroombergen, A. Stormwater, Wastewater and Climate Change: Impacts on Our Economy, Culture and Society; Deep South National Science Challenge Report prepared by Tonkin + Taylor; NIWA: Auckland, New Zealand, 2019; Available online: https://www.deepsouthchallenge. co.nz/projects/stormwater-wastewater-and-climate-change (accessed on 20 July 2020).

12. Rouse, H.L.; Bell, R.G.; Lundquist, C.J.; Blackett, P.E.; Hicks, D.M.; King, D.-N. Coastal adaptation to climate change in Aotearoa-New Zealand. N. Z. J. Mar. Freshw. Res. 2017, 51, 183-222. [CrossRef]

13. Local Government New Zealand. Vulnerable: The Quantum of Local Government Infrastructure Exposed; Local Government NZ: Wellington, New Zealand, 2019; Available online: http://www.lgnz.co.nz/ourwork/publications/vulnerable-the-quantum-of-local-government-infrastructure-exposed-to-sea-level-rise (accessed on 20 July 2020).

14. Local Government New Zealand. Exposed: Climate Change and Infrastructure; Local Government NZ: Wellington, New Zealand, 2019; Available online: https://www.lgnz.co.nz/our-work/publications/exposedclimate-change-and-infrastructure-guidance-for-councils/ (accessed on 20 July 2020).

15. Bloetscher, F.; Heimlich, B.; Meeroff, D.E. Development of an adaptation toolbox to protect southeast Florida water supplies from climate change. Environ. Rev. 2011, 417, 397-417. [CrossRef]

16. Wdowinski, S.; Bray, R.; Kirtman, B.P.; Wu, Z. Increasing flooding hazard in coastal communities due to rising sea level: Case study of Miami Beach, Florida. Ocean Coast. Manag. 2016, 126, 1-8. [CrossRef]

17. Friedrich, E.; Kretzinger, D. Vulnerability of wastewater infrastructure of coastal cities to sea level rise: A South African case study. Water SA 2012, 38, 755-764. [CrossRef]

18. Azevedo de Almeida, B.; Mostafavi, A. Resilience of infrastructure systems to sea-level rise in coastal areas: Impacts, adaptation measures, and implementation challenges. Sustainability 2016, 8, 1115. [CrossRef]

19. Su, X.; Liu, T.; Beheshti, M.; Prigiobbe, V. Relationship between infiltration, sewer rehabilitation, and groundwater flooding in coastal urban areas. Environ. Sci. Pollut. Res. 2019, 27, 14288-14298. [CrossRef] [PubMed]

20. Joyce, J.; Chang, N.B.; Harji, R.; Ruppert, T.; Imen, S. Developing a multi-scale modeling system for resilience assessment of green-grey drainage infrastructures under climate change and sea level rise impact. Environ. Model. Softw. 2017, 90,1-26. [CrossRef]

21. Controller and Auditor-General. Reflecting on Our Work about Water Management; Controller and Auditor General: Wellington, New Zealand, 2020; Available online: https://oag.parliament.nz/2020/watermanagement/docs/water-management.pdf (accessed on 20 July 2020).

22. Chester, M.V.; Underwood, B.S.; Samaras, C. Keeping infrastructure reliable under climate uncertainty. Nat. Clim. Chang. 2020, 10, 488-490. [CrossRef]

23. Hanna, C.; White, I.; Glavovic, B. Managed Retreat in New Zealand: Revealing the Terminology, Approaches and Direction of Local Planning Instruments; Report for the Resilience to Nature's Challenges National Science Challenge; The University of Waikato: Waikato, New Zealand, 2017; Available online: https://resiliencechallenge.nz/wp-content/uploads/2018/07/Hanna-C.-White-I.-Glavovic-B.-2017-

Managed-retreat-in-New-Zealand-revealing-the-terminology-approaches-and-direction-of-localplanning-instruments.pdf (accessed on 1 October 2019).

24. Lawrence, J.; Boston, J.; Bell, R.; Olufson, S.; Kool, R.; Hardcastle, M.; Stroombergen, A. Implementing pre-emptive managed retreat: Constraints and novel insights. Curr. Clim. Chang. Rep. 2020, 6, 66-80. [CrossRef]

25. Siders, A.; Hino, M.; Mach, K. The case for strategic and managed retreat in response to climate change. Science 2019, 365, 761-763. [CrossRef]

26. Lawrence, J.; Bell, R.; Blackett, P.; Stephens, S.; Allan, S. National guidance for adapting to coastal hazards and sea-level rise: Anticipating change, when and how to change pathway. Environ. Sci. Policy 2018, 82, 100-107. [CrossRef]

27. Haasnoot, M. Anticipating Change; Sustainable Water Policy Pathways for an Uncertain Future. Ph.D. Thesis, University of Twente, Twente, The Netherlands, 2013. [CrossRef]

28. Gibbs, M.T. Why is coastal retreat so hard to implement? Understanding the political risk of coastal adaptation pathways. Ocean Coast. Manag. 2016, 130,107-114. [CrossRef]

29. Haasnoot, M.; van 't Klooster, S.; van Alphen, J. Designing a monitoring system to detect signals to adapt to uncertain climate change. Glob. Environ. Chang. 2018, 52, 273-285. [CrossRef] 
30. Manocha, N.; Babovic, V. Development and valuation of adaptation pathways for storm water management infrastructure. Environ. Sci. Policy 2017, 77, 86-97. [CrossRef]

31. Kapetas, L.; Fenner, R. Integrating blue-green and grey infrastructure through an adaptation pathways approach to surface water flooding. Philos. Trans. R. Soc. A 2020, 378, 20190204. [CrossRef] [PubMed]

32. Radhakrishnan, M.; Nguyen, H.Q.; Gersonius, B.; Pathirana, A.; Zevenbergen, C.; Quang Vinh, K.; Ashley, R.M. Coping capacities for improving adaptation pathways for flood protection in Can Tho, Vietnam. Clim. Chang. 2017, 149, 29-41. [CrossRef]

33. Daysh, M. Greater Wellington; Preparing Coastal Communities for Climate Change, Assessing Coastal Vulnerability to Climate Change, Sea Level Rise and Natural Hazards; Mitchell Daysh: Auckland, New Zealand, 2019. Available online: http://www.gw.govt.nz/assets/Uploads/Wellington-Regional-Coastal-VulnerabilityAssessmentJune-2019Final.pdf (accessed on 20 July 2020).

34. Lawrence, J.; Quade, D.; Becker, J. Integrating the effects of flood experience on risk perception with responses to changing climate risk. Nat. Hazards 2014, 74, 1773-1794. [CrossRef]

35. Paulik, R.; Craig, H.; Collins, D. New Zealand Fluvial and Pluvial Flood Exposure; Deep South National Science Challenge Report prepared by NIWA; NIWA: Wellington, New Zealand, 2019; Available online: https:/www.deepsouthchallenge.co.nz/sites/default/files/201908/2019118WN_DEPSI18301_ Flood\%20Exposure_Final\%20\%281\%29.pdf (accessed on 1 November 2019).

36. White, I.; Storey, B.; Owen, S.; Bell, R.; Charters, F.; Dickie, B.; Council, R.; Foster, L.; Harvey, E.; Hughes, J.; et al. Climate Change \& Stormwater and Wastewater Systems; Motu Economic and Public Policy Research; NIWA: Wellington, New Zealand, 2017.

37. Marchau, V.A.; Walker, W.E.; Bloemen, P.J.; Popper, S.W. Decision Making under Deep Uncertainty: From Theory to Practice; Springer: Cham, Switzerland, 2019. [CrossRef]

38. Haasnoot, M.; Warren, A.; Kwakkel, J.H. Dynamic adaptive policy pathways (DAPP). In Decision Making under Deep Uncertainty: From Theory to Practice; Marchau, V.A., Walker, W.E., Bloemen, P.J., Popper, S.W., Eds.; Springer: Cham, Switzerland, 2019; pp. 71-92. [CrossRef]

39. Lawrence, J.; Haasnoot, M. What it took to catalyse uptake of dynamic adaptive pathways planning to address climate change uncertainty. Environ. Sci. Policy 2017, 68, 47-57. [CrossRef]

40. Kench, P.S.; Ryan, E.J.; Owen, S.; Bell, R.; Lawrence, J.; Glavovic, B.; Blackett, P.; Becker, J.; Schneider, P.; Allis, M.; et al. Co-creating resilience solutions to coastal hazards through an interdisciplinary research project in New Zealand. J. Coast. Res. 2018, 85, 1496-1500. [CrossRef]

41. Stephens, S.A.; Bell, R.G.; Lawrence, J. Developing signals to trigger adaptation to sea-level rise. Environ. Res. Lett. 2018, 13, 104004. [CrossRef]

42. Babovic, F.; Mijic, A.; Madani, K. Decision making under deep uncertainty for adapting urban drainage systems to change. Urban Water J. 2018, 15, 552-560. [CrossRef]

43. Hounjet, M.; Kieftenburg, M.; Altamirano, A. Learning from Flood Events on Critical Infrastructure: Relations and Consequences for Life and Environment (Circle); Deltares: Delft, The Netherlands, 2015; Available online: https://www.deltares.nl/app/uploads/2015/04/Learning-on-flood-events-on-CIrcle.pdf (accessed on 1 November 2019).

44. Schmidt, J.; Matcham, I.; Reese, S.; King, A.; Bell, R.; Henderson, R.; Smart, G.; Cousins, J.; Smith, W.; Heron, D. Quantitative multi-risk analysis for natural hazards: A framework for multi-risk modelling. Nat. Hazards 2011, 58, 1169-1192. [CrossRef]

45. Siekmann, T.; Siekmann, M. Resilient urban drainage-Options of an optimized area-management. Urban Water J. 2015, 12, 44-51. [CrossRef]

46. Olufson, S. Managed Retreat Components and Costing in a Coastal Setting. Master's Thesis, Victoria University of Wellington, Wellington, New Zealand, 2019.

47. Hodder, J. Climate change litigation: Who's afraid of creative judges? In Legal Opinion Piece for Local Government NZ; Local Government NZ: Wellington, New Zealand, 2019; p. 12. Available online: https://www.lgnz.co.nz/ assets/Uploads/f488365773/Climate-change-litigation-Whos-afraid-of-creative-judges.pdf.2019 (accessed on 20 July 2020).

48. Boston, J.; Lawrence, J. Funding climate change adaptation: The case for a new policy framework. Policy Q. 2018, 14, 40-49. [CrossRef]

49. Hanna, C.; White, I.; Glavovic, B. The uncertainty contagion: Revealing the interrelated, cascading uncertainties of managed retreat. Sustainability 2020, 12, 736. [CrossRef] 
50. Hino, M.; Field, C.B.; Mach, K.J. Managed retreat as a response to natural hazard risk. Nat. Clim. Chang. 2017, 7, 364-370. [CrossRef]

51. Ministry for the Environment. New Zealand National Climate Change Risk Assessment; Ministry for the Environment: Wellington, New Zealand, 2020. Available online: https://www.mfe.govt.nz/climate-change/ assessing-climate-change-risk (accessed on 1 October 2020).

Publisher's Note: MDPI stays neutral with regard to jurisdictional claims in published maps and institutional affiliations.

(C) 2020 by the authors. Licensee MDPI, Basel, Switzerland. This article is an open access article distributed under the terms and conditions of the Creative Commons Attribution (CC BY) license (http://creativecommons.org/licenses/by/4.0/). 